\title{
Simulation Study on the Effect of Coal Seam Hydraulic Fracturing to Increase Permeability
}

\section{Kai Wang ( $\nabla$ kaiwang@cumtb.edu.cn )}

China University of Mining and Technology (Beijing)

\section{Guodong Zhang}

China University of Mining and Technology (Beijing)

\section{Yanhai Wang}

China University of Mining and Technology (Beijing)

\section{Xiang Zhang}

China University of Mining and Technology (Beijing)

\section{Kangnan Li}

China University of Mining and Technology (Beijing)

Wei Guo

China University of Mining and Technology (Beijing)

\section{Feng Du}

China University of Mining and Technology (Beijing)

\section{Research}

Keywords: Fracturing simulation, Gas drainage, Fracturing effect prediction, Numerical model

Posted Date: August 17th, 2021

DOI: https://doi.org/10.21203/rs.3.rs-806067/v1

License: (c) (i) This work is licensed under a Creative Commons Attribution 4.0 International License.

Read Full License 


\title{
Simulation Study on the Effect of Coal Seam Hydraulic Fracturing to
}

\section{Increase Permeability}

\author{
Kai Wang ${ }^{1,2,3, *}$, Guodong Zhang ${ }^{1,2,3}$, Yanhai Wang ${ }^{1,2,3}$, Xiang Zhang ${ }^{1,2,3}$, Kangnan $\mathrm{Li}^{1,2,3}$, Wei Guo ${ }^{1,2,3}$, Feng Du ${ }^{1,2,3, *}$ \\ ${ }^{1}$ Beijing Key Laboratory for Precise Mining of Intergrown Energy and Resources, China University of Mining and Technology \\ (Beijing), Beijing 100083, China \\ ${ }^{2}$ School of Emergency Management and Safety Engineering, China University of Mining and Technology (Beijing), Beijing \\ 100083, China \\ ${ }^{3}$ State Key Laboratory of Coal Resources and Safe Mining, China University of Mining and Technology (Beijing), Beijing \\ 100083, China
}

\section{E-mail: kaiwang@cumtb.edu.cn; fdu@cumtb.edu.cn}

\begin{abstract}
Hydraulic fracturing is mainly used to improve coal seam permeability, extract coal seam gas and prevent coal-gas outburst. However, in the aspect of anti-reflection effect, it is judged by the method of field inspection, and there is no good prediction method before the engineering application. In this work, PFC2D software is used to simulate the process of coal seam hydraulic fracturing, and the results are introduced into the mathematical coupling model of the interaction between coal seam deformation and gas flow for analysis. The results show that the particles are moving towards the direction of the minimum principal stress, the moving speed of the particles at the crack tip increases, and the crack will finally expand towards the direction of the maximum principal stress. The gas pressure decline rate and permeability increase rate of the fractured model are both higher than that of the unfractured model. With the increase of extraction time, the decrease rate of gas pres sure and the increase rate of permeability both decrease rapidly and gradually approach 0 . The longer the hydraulic fracturing time is, the more complex the fracture network is, and the faster the gas pressure drops. However, the difference between the horizontal and vertical gas pressure drops will become larger and larger, and the impact of fracturing on gas drainage effect will gradually become smaller. With the increase of fracturing time, the difference of permeability increase at different monitoring points becomes larger and larger, but with the increase of gas drainage time, the difference will gradually decrease. The higher the initial void pressure is, the faster the gas pressure drops and the greater the permeability increase. However, the influence of the
\end{abstract}


initial void pressure on the permeability increase will gradually become smaller. The research results could provide certain guidance for the prediction of anti-reflection effect of hydraulic fracturing in underground coal mines.

Keywords: Fracturing simulation; Gas drainage; Fracturing effect prediction; Numerical model 


\section{Introduction}

Gas disaster is still one of the important factors restricting mine safety. With the increase of mining depth and intensity in China, many low gas mines have been transformed into high gas or even gas outburst mines, and the safety situation is not ideal [1-4]. Coal bed methane exploitation can not only prevent coal and gas outburst, but also provide clean energy. With the increase of mining depth, the in-situ stress becomes larger, the permeability of coal seam becomes lower, and the difficulty of coalbed methane exploitation increases [5-7]. Therefore, how to effectively improve the permeability and prevent gas disaster is one of the most important problems in the development of coalbed methane [8-11]. The research shows that hydraulic fracturing can well increase the permeability of coal seam, which is conducive to the exploitation of coalbed methane and the prevention of coal and gas outburst [12-14].

Hydraulic fracturing of coal seam is to inject high-pressure liquid into coal seam from borehole by high-pressure pump, and use high-pressure liquid to produce pressure to overcome in-situ stress, tensile strength and cohesion of coal seam, so as to produce fracture and form fracture network channel of gas flow. Based on PFC2D software, Wang et al. [14] studied the effect of macro mechanical properties on crack initiation and size. The results show that the main fracture extends to the direction of maximum principal stress. Wang et al. [15] used the finite element mesh method to study the fracture propagation mechanism of hydraulic fracturing in coal seam with discontinuous natural fractures. The results show that under the condition of high stress difference, the hydraulic fracture network is spindle shaped, multi-level branch structure, and the secondary fracture accounts for a large proportion, which is an important part of the hydraulic fracture network of coal seam. Lyu et al. [16] analyzed the influence of natural fractures in coal seams on hydraulic fracturing, and the results show that the propagation of hydraulic fractures is controlled by the direction of natural fractures and principal stress. Yuan et al. [17] established the mathematical model of hydraulic fracturing in low permeability coal seam, and analyzed the characteristics of hydraulic fracturing expansion under the influence of water injection pressure and other factors. The results show that with the increase of injection pressure, the fracture length increases linearly, and the fracture width increases exponentially. The fracture width will be greater than the fracture length in the later stage of fracturing. Zhao et al. [18] studied the influence of coal rock type (bright coal, semi-bright coal, semi-dark coal and dark coal) and perforation location on hydraulic fracture propagation. It is found that the fracture morphology and proppant distribution of bright briquette are better than that of dark briquette.

As shown above, a large number of scholars have studied the fracture propagation form, fracturing influence range and the influence of original fracture on fracturing by means of experiments and simulation [19-21]. However, in terms of permeability 
enhancement effect of hydraulic fracturing, most of them are judged by means of on-site detection. Zhang et al. [22] conducted a hydraulic fracturing test study on the Nantong Mine in the southeast of the Sichuan Basin. Field investigations show that hydraulic fracturing can significantly increase the methane extraction rate of boreholes, which is more than 10 times higher than that of conventional boreholes. The field research of Huang et al. [23] shows that the hydraulic fracturing technology can improve the gas permeability under downhole conditions, and the gas drainage capacity could increase by 15 times. The field application results of pulse hydraulic fracturing [24] show that the proportion of micropores decreases by $7.7 \%$, the proportion of mesopores increases by $23.1 \%$, and the proportion of macropores increases by $2.9 \%$, which significantly improves the permeability of coalbed methane reservoir. In the work of Li et al. [25], after applying the hydraulic fracturing method, the gas desorption index $k_{1}$ of the driving face fell below the critical value. The gas drainage volume of fracturing boreholes and pilot boreholes increased by 3.32 times and 3.07 times respectively compared with normal boreholes.

Although many scholars have studied the development of coalbed methane and the impact of hydraulic fracturing on coal seam, the research on the permeability enhancement effect of hydraulic fracturing is insufficient, and there is no good method to predict the permeability enhancement effect of coal seam before field application. In this paper, PFC discrete element software is used for hydraulic fracturing simulation, and the connected fractures are extracted and imported into COMSOL Multiphysics numerical analysis software for gas drainage simulation, so as to evaluate the permeability enhancement effect of hydraulic fracturing of coal seam. The research results are expected to provide help for the prediction of anti-reflection effect of hydraulic fracturing in underground coal mines.

\section{Simulation of fracturing with PFC}

\subsection{Hydraulic coupling model}

In this paper, based on PFC5.0 computing platform, a discrete element fluid structure coupling model for hydraulic fracturing is established. The fluid is stored in a pore grid, as shown in Fig. 1. Fluid exchange can take place in the adjacent pore grid under the effect of fluid pressure difference. The coupling mode of fluid and solid is mainly through the change of contact force to realize the change of channel pore. The pressure is changed by changing the mechanical characteristics of the study area, and the pore pressure of the area has a pushing effect on the particles inside.

The flow rate of fluid exchange can be expressed by Hagen Poiseuille equation [26, 27]: 


$$
q=k a^{3} \frac{\square p}{L}
$$

Where $q$ is the flow rate, $a$ is the opening of the fluid channel, which is related to the normal force of the two particles, $k$ is the permeability coefficient, $\square p$ is the pressure difference between the two pore basins, and $L$ is the length of the fluid channel.

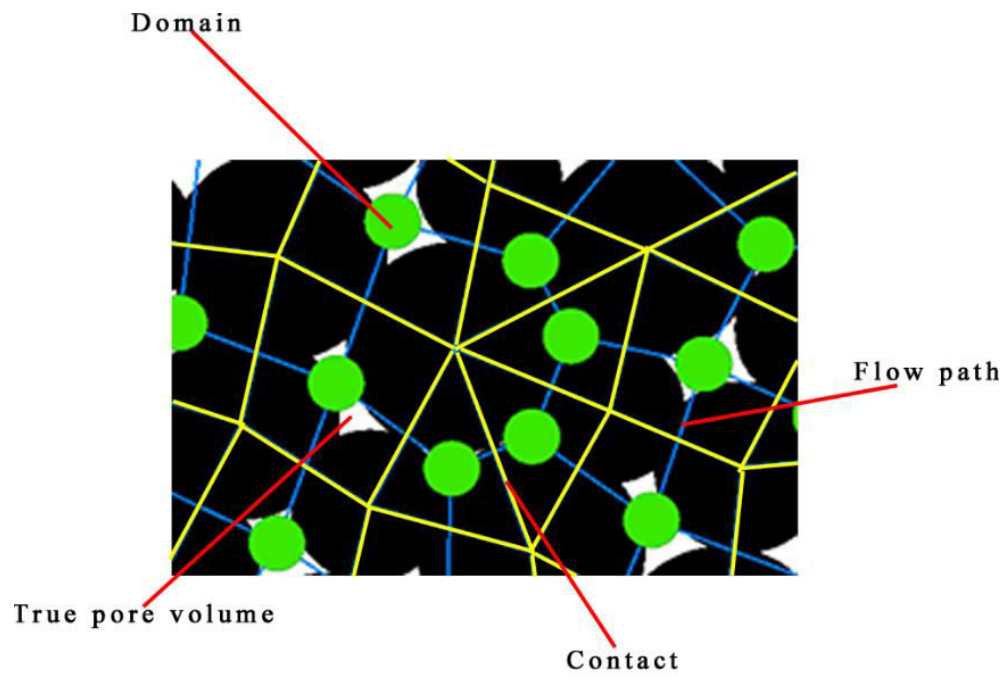

Fig. 1. Watershed and flow path in particle binding model

When the bond between the two particles is broken, the opening $a$ is [26]:

$$
a=a_{0}+\lambda\left(d-R_{1}-R_{2}\right)
$$

Where, $d$ is the distance between two particles, $R_{1}$ and $R_{2}$ are the radii of two particles respectively, and $\lambda$ is the dimensionless multiplier.

In time $\square t$, the change in pore fluid pressure due to fluid flow is [26, 27]:

$$
\square p=\frac{K_{f}}{V_{d}}\left(\sum q \square t-\square V_{d}\right)
$$

In the formula, $K_{f}$ is the compressive modulus of the fluid, $V_{d}$ is the "domain", that is the pore volume, $\square V_{d}$ is the pore volume change, and $\sum q$ is the total flow of the fluid.

\subsection{Parameter calibration}

Parameter calibration is to correspond the macro-mechanical properties measured in the laboratory with the 
meso-mechanical properties through simulation experiments, so as to obtain the meso-mechanical parameters for simulation. The PFC contact model used for rock and soil mechanics analysis is linear parallel bonding model ( $\mathrm{Pb}$ model). The microscopic parameters of $\mathrm{Pb}$ model have a certain correspondence with the macro-mechanical parameters, and the microscopic parameters can be calibrated by uniaxial compression test and uniaxial tensile test. As shown in Table 1, a model with a width of $1 \mathrm{~m}$ and a height of $2 \mathrm{~m}$ was adopted for simulation. The particle radius selection has a uniform distribution between the maximum and minimum radii. The minimum radius is $0.01 \mathrm{~m}$, the ratio of maximum radius to minimum radius is 1.6 , and the porosity is 0.06 .

Table 1 Simulation basic parameters

\begin{tabular}{ccc}
\hline Size & Uniaxial tension & Uniaxial compression \\
\hline Sample size $(\mathrm{m})$ & Width $*$ height $=1 * 2$ & Width $*$ height $=1 * 2$ \\
Minimum radius $(\mathrm{m})$ & 0.01 & 0.01 \\
Maximum radius $(\mathrm{m})$ & 0.016 & 0.06 \\
Porosity & 0.06 & 3467 \\
Particle number & 3467 & 1600 \\
Particle density $\left(\mathrm{kg} / \mathrm{m}^{3}\right)$ & 1600 &
\end{tabular}

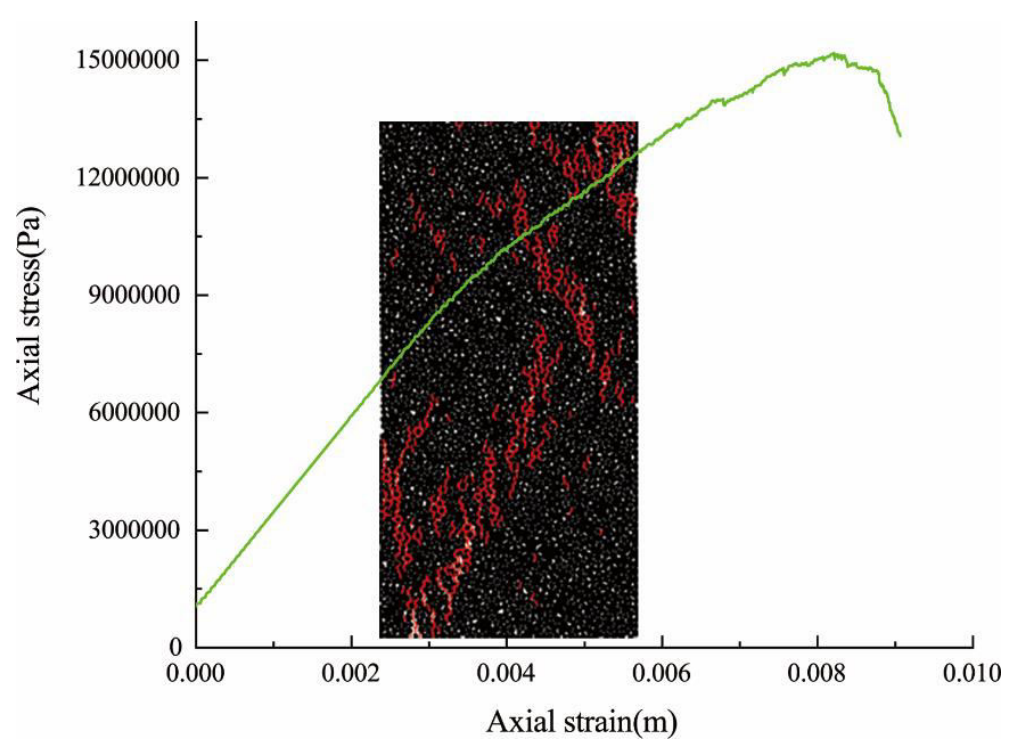

(a) 


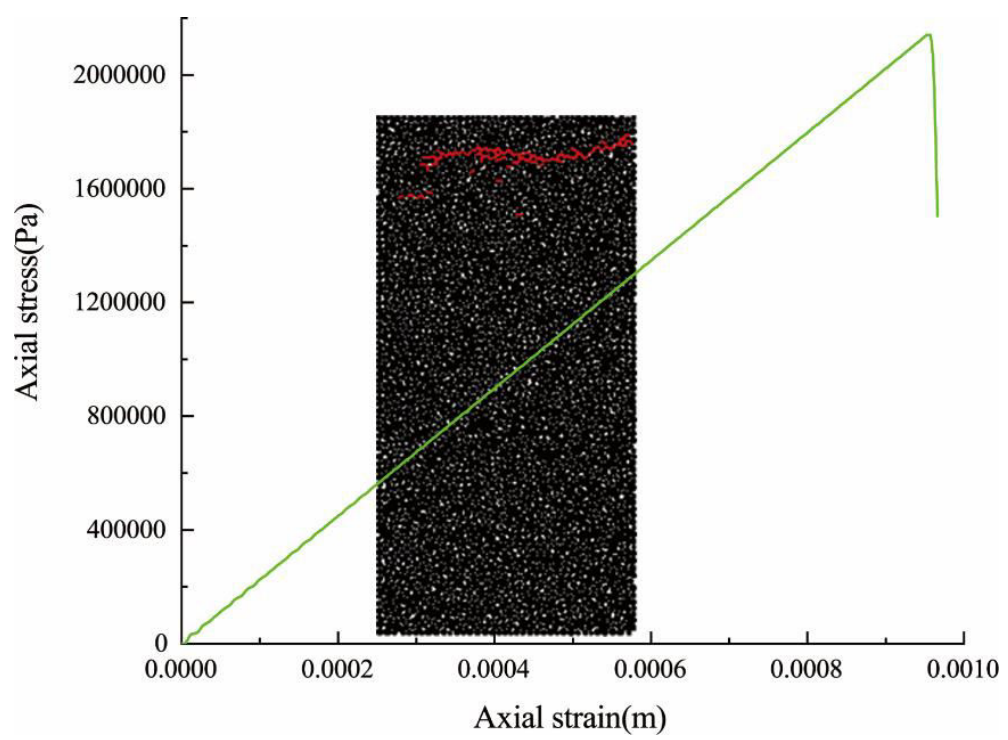

(b)

Fig. 2. Numerical experiments: (a) Uniaxial compression (b) Uniaxial tension (Red line indicates crack)

In this paper, uniaxial compression and uniaxial tension numerical experiments are used to calibrate the parameters. The calibration effect is shown in Fig. 2, and the meso-mechanical parameters after calibration are shown in Table 2. Using the data in Table 2 to perform uniaxial compression and uniaxial tension simulations, the macroscopic mechanical properties corresponding to the meso-mechanical parameters can be obtained. It can be seen from Table 3 that the measured and simulated macroscopic mechanical properties are very similar.

Table 2 Calibrated micromechanical parameters

Micromechanical parameters

Emod (GPa)

$\mathrm{Pb} \_$emod $(\mathrm{GPa})$

Linear_kratio

Pb_kratio

Pb_ten $(\mathrm{MPa})$

$\mathrm{Pb} \_$coh $(\mathrm{MPa})$
Calibration value

0.546

7.2

3.38

3.38

Table 3 Comparison of measured and simulated macro mechanical properties

Name

Measured values of macroscopic

mechanical properties
The value of macroscopic mechanical properties of simulation 
Elastic modulus $(\mathrm{GPa})$

Poisson's ratio

Uniaxial compressive strength

(MPa)

Uniaxial tensile strength (MPa)
3

0.3

0.296

15.0

2.0
3.15

2.1

\subsection{Analysis of fracturing effect}

The numerical model of this study is a two-dimensional model, as shown in Fig. 3. The length and width of the model are all $5 \mathrm{~m}$, the minimum and maximum radius of the particles are $0.01 \mathrm{~m}$ and $0.016 \mathrm{~m}$ respectively, and the distribution is uniform between the maximum radius and the minimum radius. The number of particles in the model is 43457 . The initial stress is simulated by adjusting the wall speed, so that the horizontal stress of the model reaches $5 \mathrm{MPa}$ and the vertical stress is $8 \mathrm{MPa}$. The fracturing water injection hole is located in the middle of the model with a drilling radius of $0.1 \mathrm{~m}$, and then the fluid is injected at a rated pressure of $15 \mathrm{MPa}$. The mechanical model of the coal seam is a linear parallel bonding model, and the parameter values are the micro-mechanical parameters calibrated in section 2.2.

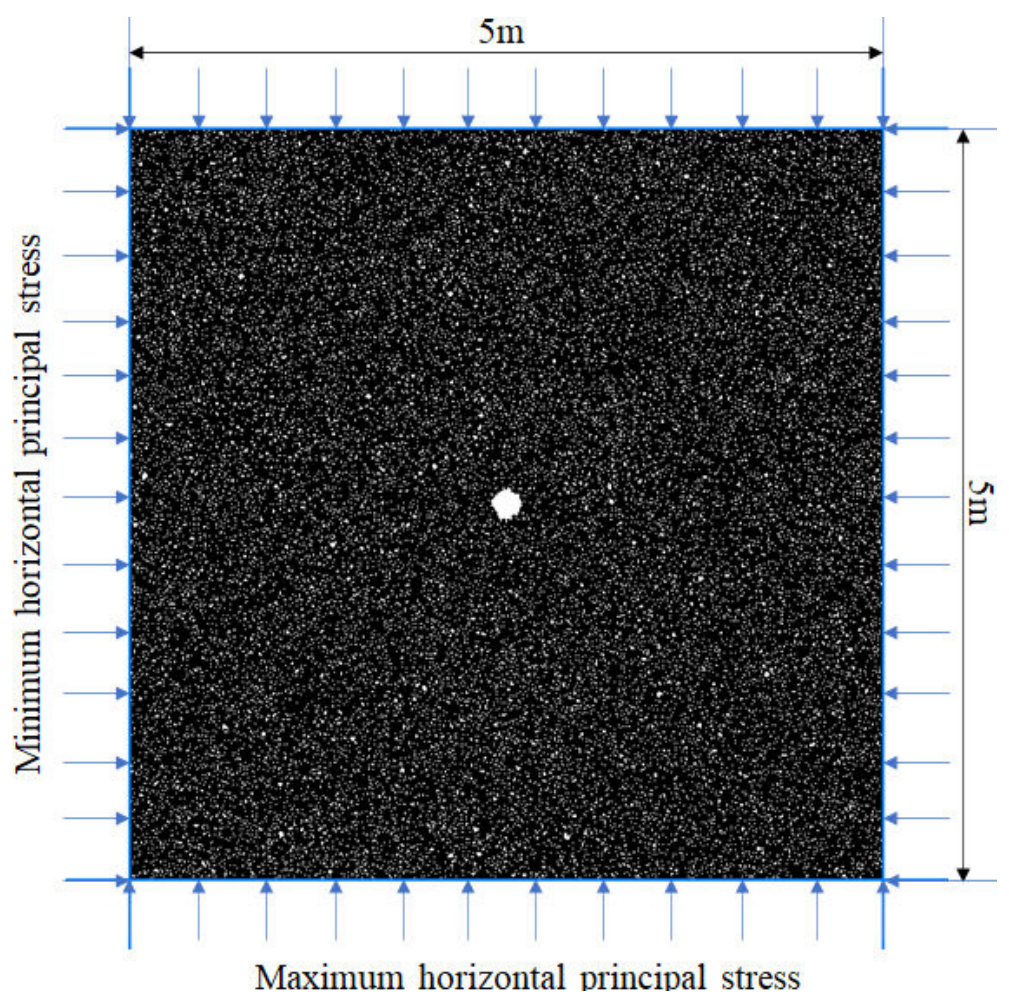

Fig. 3. PFC2D model before injection

Due to the long-term triaxial stress of overlying strata, the coal seam has a certain strength. According to the stress 
conditions around the fracturing hole and the classical fracturing theory, many scholars have analyzed that the fracture pressure is related to the horizontal effective stress, tensile strength and pore pressure [25]. Therefore, the fracture pressure of the coal seam can be calculated by the following formula:

$$
P_{i n i}=3 \bar{\sigma}_{3}-\bar{\sigma}_{1}+P_{\text {pore }}+\sigma_{t}
$$

In the formula, $\sigma_{t}$ is the tensile strength of coal seam (MPa). $\bar{\sigma}_{1}$ and $\bar{\sigma}_{3}$ are the horizontal maximum and minimum principal stress $(\mathrm{MPa})$, respectively. $P_{\text {pore }}$ is the pore pressure.

By creating a measuring circle to record the pressure of the sphere near the injection hole, the curve of the injection pressure and the number of cracks over time is established, as shown in Fig. 4. The peak pressure of $7.42 \mathrm{MPa}$ is called the burst pressure. The rupture pressure of the model calculated by the above formula is $9 \mathrm{MPa}$, which is $1.58 \mathrm{MPa}$ different from the simulated rupture pressure of 7.42 MPa. This may be related to the excessively large initial pressure of the model and the short accumulation of pressure. As the liquid is continuously injected from the injection orifice, the liquid accumulates in the injection orifice and the previously formed fracture. With the passage of time, the pressure at the crack tip continues to rise until it reaches the fracture pressure of the coal seam, and new cracks will appear in the coal seam, which will cause the pressure at the injection orifice to drop again. Therefore, the injection pressure curve is serrated and the fracture will continue to expand. It can be seen from Fig. 4 that as the fracturing time increases, the rate of fracture propagation changes from fast to slow. Moreover, the crack propagation is discontinuous, and the pressure at the tip of the crack is not enough to damage the coal body for some time, and the crack will continue to expand after the pressure has accumulated to the failure pressure.

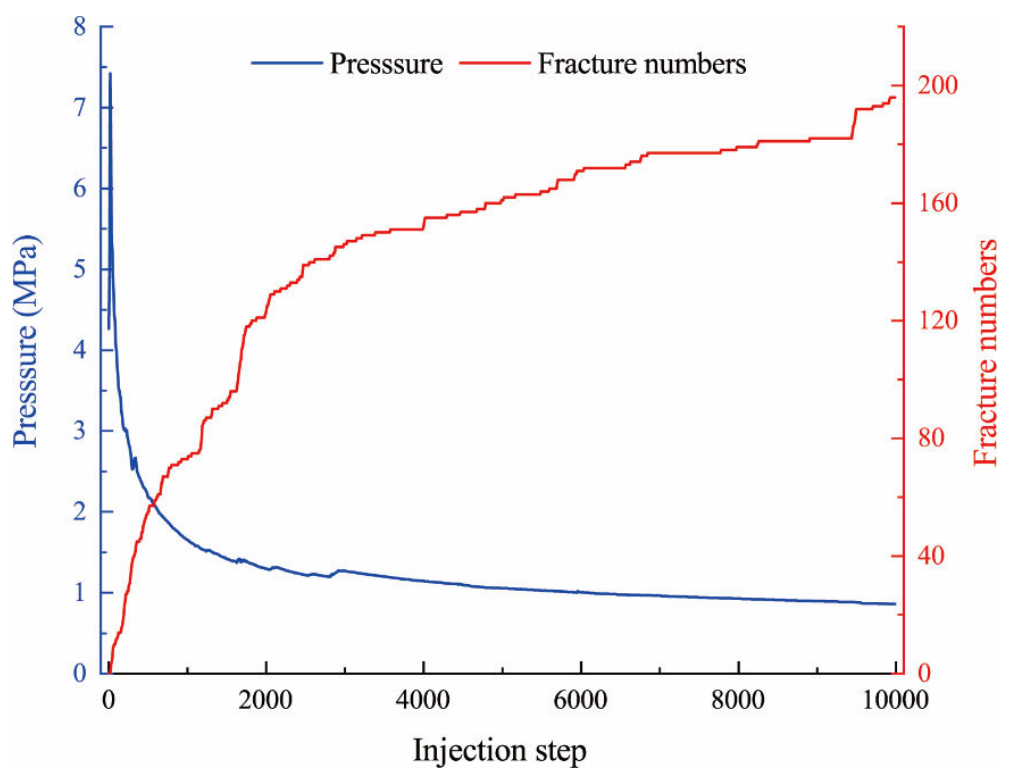


Fig. 4. Injection pressure and fracture growth curve

The fracturing effect at different time steps is shown in Fig. 5. The fractures expand in both the horizontal and vertical directions, but the fractures still mainly expand in the direction of the maximum principal stress. When the fracturing reached 100,000 steps, the propagation distance of the fracture reached $2.38 \mathrm{~m}$. As shown in Fig. 6(a), the fracturing fluid flowing into the fracture continues to accumulate pressure at the fracture tip. Under the combined action of liquid pressure and ground stress, the horizontal force of the particles at the fracture tip (the direction of the minimum principal stress) increases. As a result, its horizontal speed increase. Eventually the particles will move in the direction of the minimum principal stress, and the cracks will continue to expand in the direction of the maximum principal stress. As shown in Fig. 6(b), the particles are all moving in the direction of the minimum principal stress, and the closer they are to the injection hole, the greater the displacement, the more adequate the crack propagation will be.

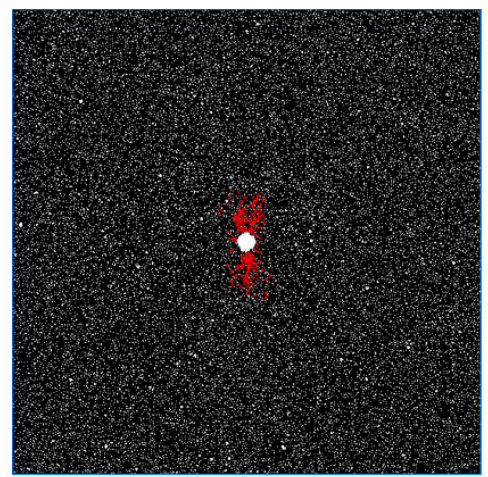

step 10000

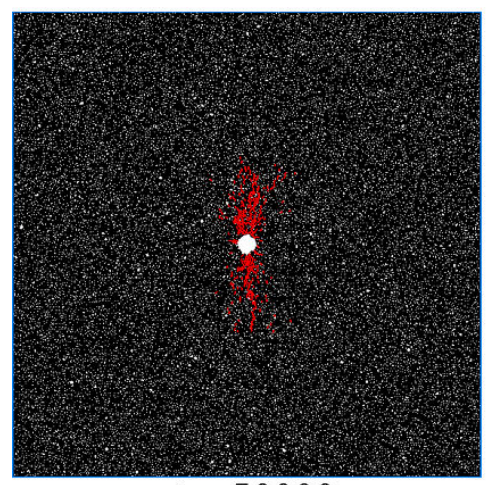

step 70000

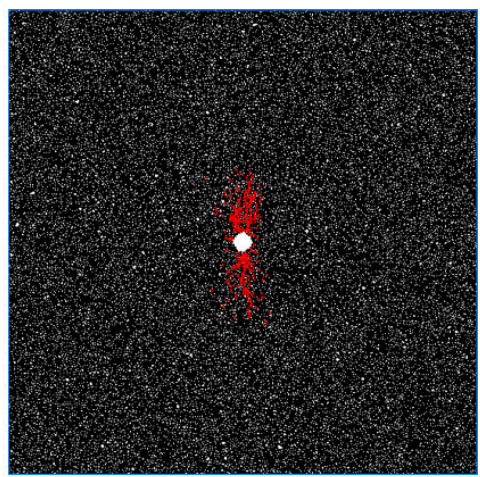

step40000

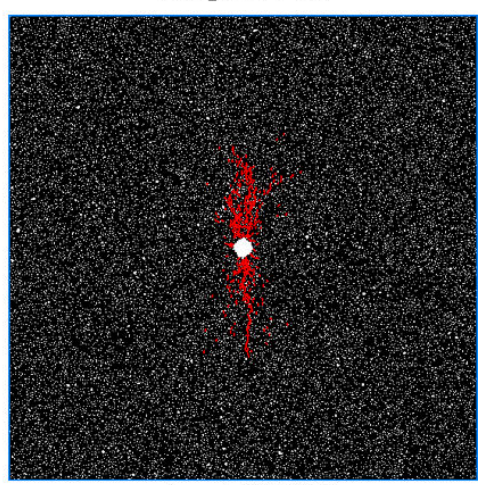

step 100000

Fig. 5. Fracturing effect diagram at different time steps 


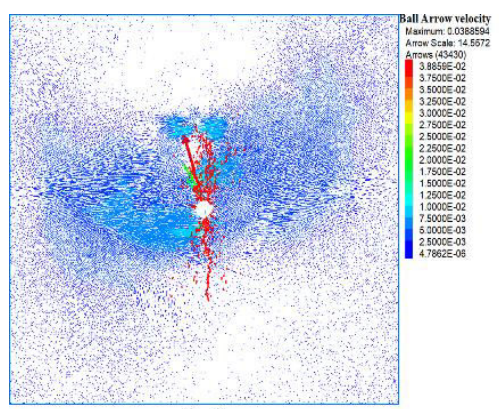

(a)

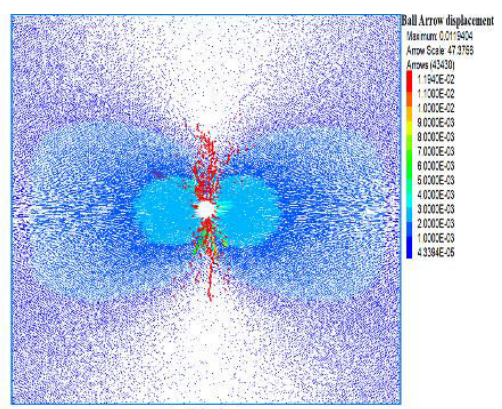

(b)

Fig. 6. Particle vector diagram under 100,000 fracturing steps: (a) Velocity diagram (b) Displacement diagram

\section{Model and simulation scheme determination}

\subsection{Model building}

Based on the theory of poroelasticity and seepage mechanics [28], Zhang et al. [29] established a fully coupled mathematical model of coal deformation and gas flow considering the deformation of adsorption and desorption.

\subsubsection{Control equation of coal seam deformation}

According to the total strain equation of coal, combined with Langmuir volume strain equation $\varepsilon_{s}=\varepsilon_{L} \frac{p}{p+p_{L}}$, balance equation $\sigma_{i j, j}+f_{i}=0$ and Cauchy equation $\sigma_{i j, j}+f_{i}=0$, the governing equation for coal deformation is obtained as:

$$
G u_{i, k k}+\frac{G}{1-2 v} u_{k, k i}-\alpha p_{, i}-K \varepsilon_{L} \frac{p_{L}}{\left(p+p_{L}\right)^{2}} p_{, i}+f_{i}=0
$$

Where $\varepsilon_{\mathrm{ij}}$ is the component of the total strain tensor, $G$ is the shear modulus of coal, $K$ is the bulk modulus of coal, $E$ is the Young's modulus of coal, $v$ is the Poisson's ratio of coal, $\mathrm{p}$ is the gas pressure in the pores. The effective stress component is defined as $\sigma_{i j}^{\prime}=\sigma_{i j}+\alpha p \delta_{i j}, \alpha=1-\mathrm{K} / \mathrm{K}_{\mathrm{s}}$ is Biot coefficient, $\mathrm{K}_{\mathrm{s}}$ is bulk modulus of coal particles, $\delta_{i j}$ is Kronecker number, $u_{i}$ is the component of displacement, $\sigma_{i j}$ is the component of the total stress tensor, $f_{i}$ is the component of the force on the object, $\varepsilon_{L}$ is the Langmuir pressure constant, and $p_{L}$ is the pore pressure. At this time, the measured volumetric strain is equal to $0.5 \varepsilon_{L}$ [30]. 


\subsubsection{Gas flow control equation}

According to the ideal gas law, mass balance equation and Darcy's law, the gas flow control equation is:

$$
\left[\phi+\frac{\rho_{c} p_{a} V_{L} p_{L}}{\left(p+p_{L}\right)^{2}}\right] \frac{\partial p}{\partial t}+p \frac{\partial \phi}{\partial t}-\nabla \cdot\left(\frac{k}{\mu} p \nabla p\right)=Q_{s}
$$

In the formula, $p_{a}$ is an atmospheric pressure $(101.325 \mathrm{kPa}), k$ is the permeability, $\mu$ is the dynamic viscosity of the gas, $\phi$ is the porosity, $\rho_{g a}$ is the gas density under standard conditions, $\rho_{c}$ is the coal density, $\rho_{g}$ is the gas density, $v_{g}$ is the Darcy velocity vector, $Q_{S}$ is the gas source, $t$ is the time, $s$ and $m$ are the gas content, including free state Gas and adsorbed gas [31].

\subsubsection{Porosity and permeability models}

It is assumed that the adsorption strain of coal is the same as the adsorption strain of the pore space. When the initial pressure is $p_{0}$, the initial porosity is $\phi_{0}$ and the initial volumetric strain is zero. According to the actual situation on site, assuming that $\varepsilon_{33}$ is the uniaxial strain direction and the overburden load direction is basically unchanged, the $\varepsilon_{11}$ and $\varepsilon_{22}$ are lateral strains, both of which are zero [30-33]. Considering the cubic law, the permeability expression under the condition of uniaxial strain and constant overburden load is:

$$
k=k_{0}\left\{1+\frac{\alpha}{\phi_{0}}\left[\frac{\alpha}{M}\left(p-p_{0}\right)+\frac{p-p_{0}}{K_{S}}+\left(\frac{\mathrm{K}}{M}-1\right) \varepsilon_{L} p_{L} \frac{\left(p-p_{0}\right)}{\left(p_{0}+p_{L}\right)\left(p+p_{L}\right)}\right]\right\}^{3}
$$

where $M$ is the limiting axial elastic modulus, $M=E(1-v) /(1+v)(1-2 v)$.

The effect of grain compression is considered for the rebound pressure of the fully coupled pore model. Under the condition that the uniaxial strain and the overburden load remain unchanged, the expression of the rebound pressure is [31]:

$$
p_{c}=\left[\frac{K_{S}(M-K) \varepsilon_{L} p_{L}}{\alpha K_{S}+M}\right]^{1 / 2}-p_{L}
$$

The partial derivative of porosity $\phi$ with respect to time $t$ is substituted into equation (6) to obtain the fully coupled control equation of gas flow under the influence of coal seam deformation:

$$
\left[\phi+\frac{\rho_{c} p_{a} V_{L} p_{L}}{\left(p+p_{L}\right)^{2}}+\frac{(\alpha-\phi) p}{K_{S}}-\frac{(\alpha-\phi) \varepsilon_{L} p_{L} p}{\left(p+p_{L}\right)^{2}}\right] \frac{\partial p}{\partial t}-\nabla \cdot\left(\frac{k}{\mu} p \nabla p\right)=Q_{S}-(\alpha-\phi) p \frac{\partial \varepsilon_{v}}{\partial t}
$$


Therefore, equations (5), (6), (7), (8) and (9) define the fully coupled model of coal seam deformation and gas flow. The coupling relationship between coal seam deformation and gas flow is shown in Fig. 7.

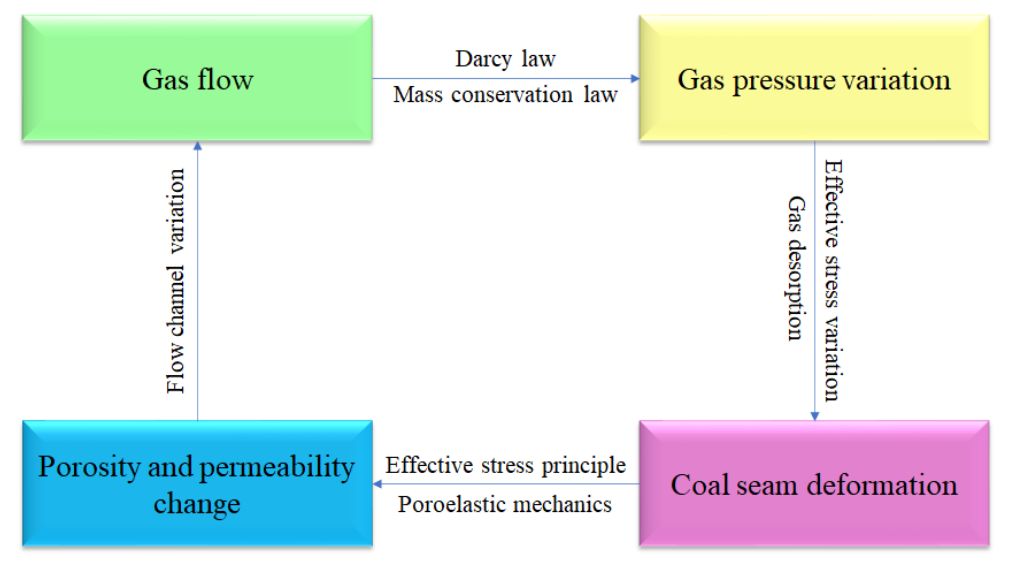

Fig. 7. Coupling relationship between coal seam deformation and gas flow

\subsection{Simulation scheme and parameters}

The above-mentioned control equations constitute a mathematical model describing coal deformation and gas flow. In this paper, COMSOL Multiphysics software is used to solve the numerical model by finite element method. Fractures are important flow channels in the process of gas drainage, so different fracturing times will lead to different fracture network conditions, which will eventually lead to different gas drainage effects, and different initial pore pressures will also affect the gas drainage effects. Therefore, in this work, we will proceed from the above two points to analyze the effects of different fracturing times and different initial pore pressures on the gas drainage effect. The specific simulation schemes are shown in Table 4.

Table 4 Experimental conditions of different samples

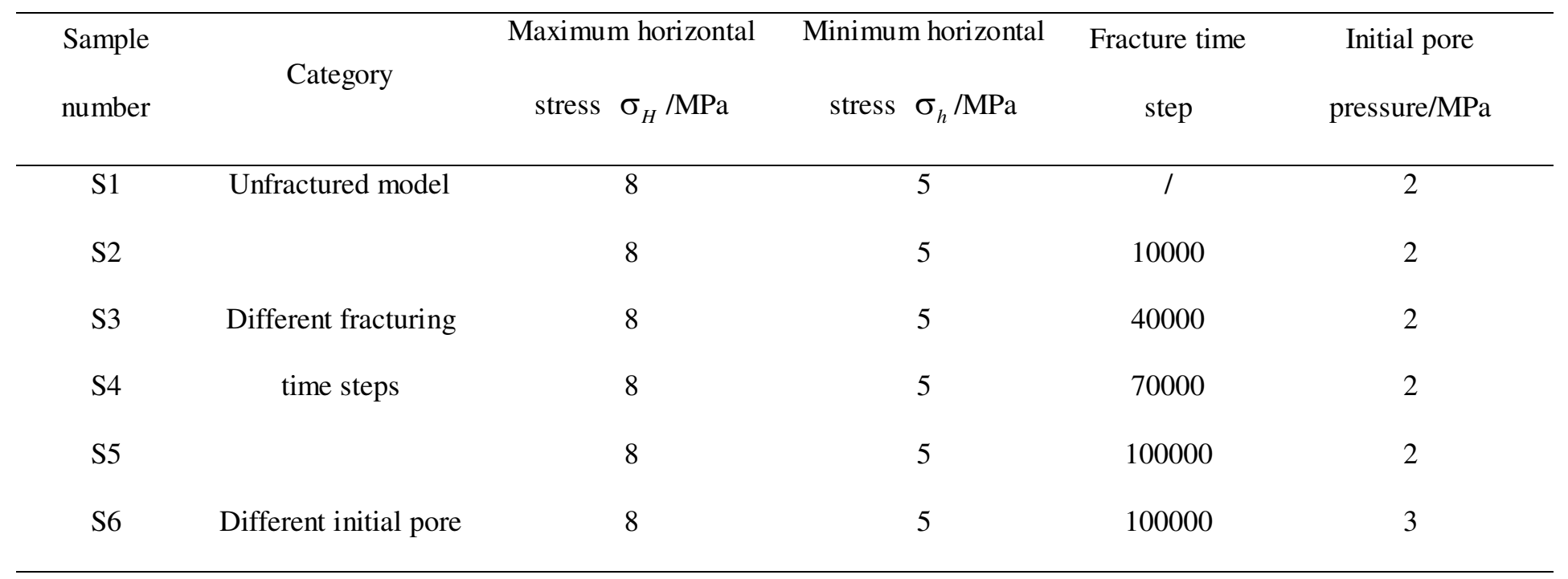


S7

S8 pressures

8
100000

100000

Firstly, the fracture propagation effect diagram under different fracturing time steps in Section 2.3 is imported into CAD, and its connected fractures are extracted respectively, as shown in Fig. 8. Then it is imported into COMSOL Multiphysics software. In order to ensure the integrity of fracture boundary, the calculation grid is densified. The final gas drainage physical model is shown in Fig. 9. The final physical model of gas drainage is shown in Fig. 9. The size of the model is all $5 * 5 \mathrm{~m}$, the suction pressure is set to one atmosphere, and the boundary of the model is set to roll support. The main parameters used in the numerical simulation are shown in Table 5 .

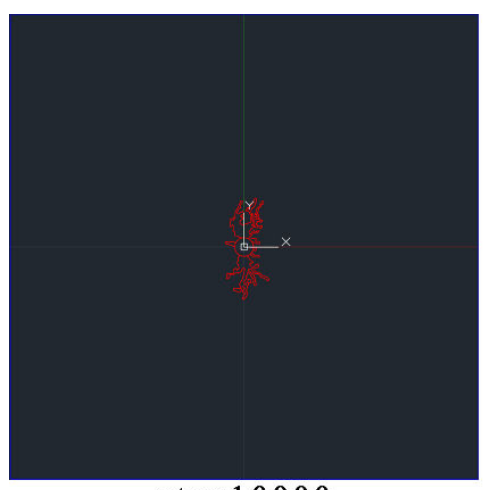

step 10000

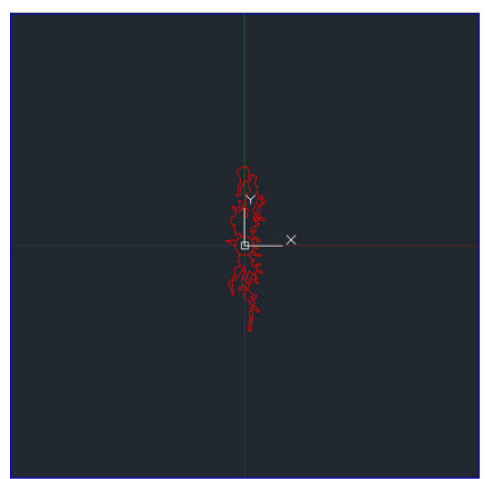

step70000

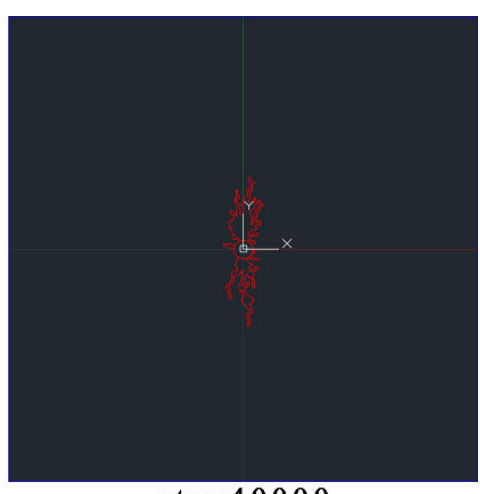

step40000

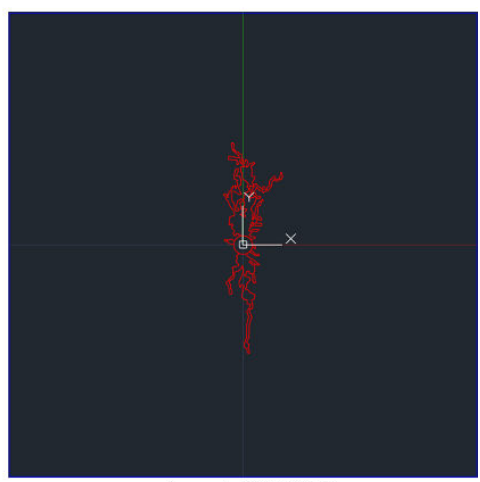

step 100000

Fig. 8. CAD extraction of fracture propagation effect diagram of different fracturing time steps 

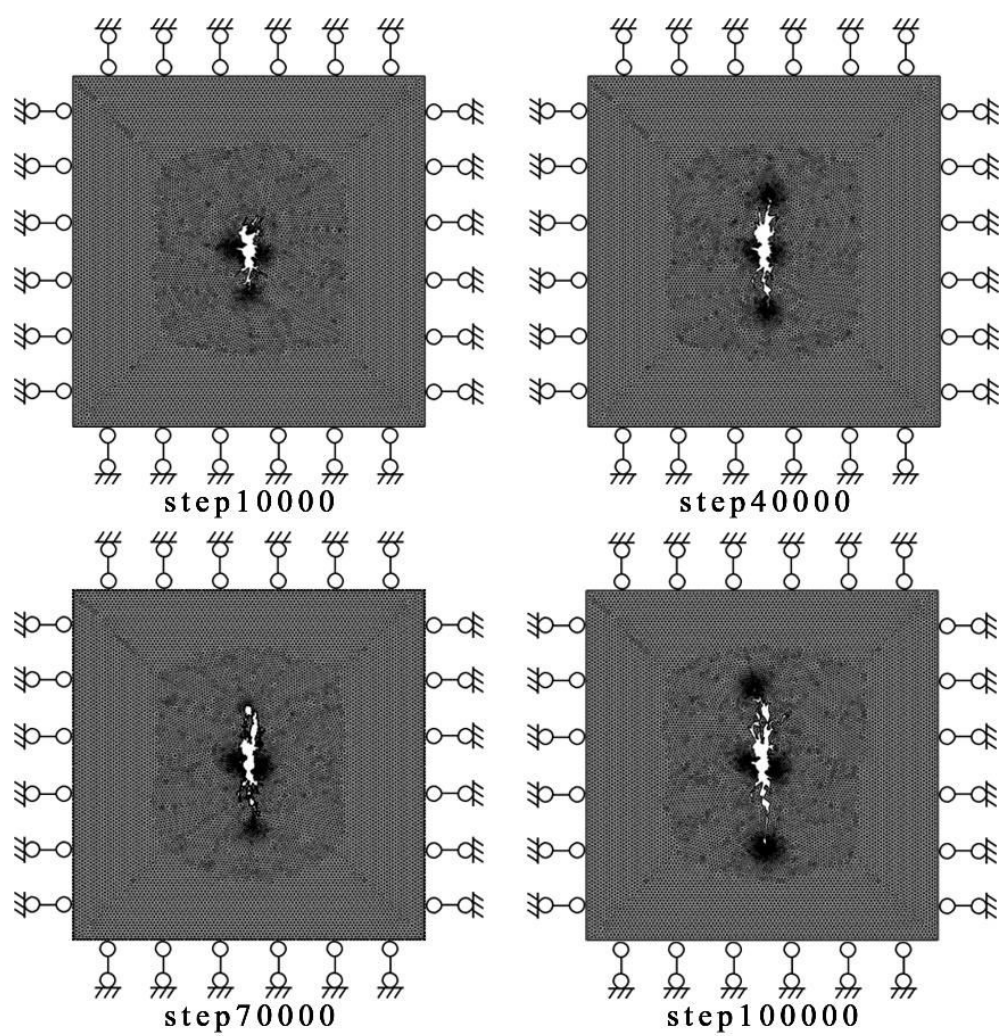

Fig. 9. Gas drainage physical model under different fracturing time steps

Table 5 Main parameters used in numerical simulation

\begin{tabular}{|c|c|c|c|}
\hline Name & Symbol & Unit & Value \\
\hline Young's modulus of coal & $E$ & $\mathrm{GPa}$ & 3 \\
\hline Young's modulus of coal grains & $E_{S}$ & $\mathrm{GPa}$ & 4.5 \\
\hline Passion's ratio of coal & $v$ & / & 0.3 \\
\hline Density of coal & $\rho_{c}$ & $\mathrm{~kg} / \mathrm{m}^{3}$ & $1.6 \mathrm{e} 3$ \\
\hline Methane dynamic viscosity & $\mu$ & $\mathrm{Pa} \cdot \mathrm{s}$ & $1.84 \mathrm{e}-5$ \\
\hline Langmuir pressure constant & $P_{L}$ & $\mathrm{MPa}$ & 6.1 \\
\hline Langmuir volume constant & $V_{L}$ & $\mathrm{~m}^{3} / \mathrm{kg}$ & 0.015 \\
\hline Initial porosity of coal & $\phi_{0}$ & l & 0.06 \\
\hline Initial permeability of coal & $k_{0}$ & $\mathrm{~m}^{2}$ & $5 e-17$ \\
\hline Langmuir volumetric strain constant & $\varepsilon_{L}$ & I & 0.02295 \\
\hline
\end{tabular}




\section{Results and discussion}

\subsection{Fractured and unfractured models}

The mathematical model established in this paper is applied to the physical model and numerically solved. Fig. 10(a) and Fig. 10(b) show the gas pressure distribution of the unfractured model (S1) and the fractured model (S5) at different times of drainage. The results showed that the gas pressure decreased rapidly in the first few days, but decrease rate of gas pressure decreased slowly with the increase of the drainage time, and the gas pressure of the fracturing model always decreased faster than that of the unfractured model. In the fracturing model, there are differences in the distribution of gas pressure in the horizontal and vertical directions. The gas pressure in the vertical direction of the main direction of fracture propagation is always smaller than the horizontal direction. In order to quantitatively analyze the change of gas pressure over time, a detection point $(1.5,0)$ in the unfractured model (because the model is symmetric in the $\mathrm{X}$ and $\mathrm{Y}$ directions, only one monitoring point needs to be set) is set, and two in the fracturing model are set. The detection points are respectively monitoring point $1(1.5,0)$ and detection point $2(0,1.5)$, as shown in Fig. 11. The results show that the gas pressure change trend of the two models is the same. The gas pressure drops quickly at the beginning of the drainage, and the gas pressure decline rate rapidly decays and approaches zero as the drainage time increases. The gas pressure of the fracturing model decreases faster than that of the unfractured model. In the fracturing model, the gas pressure decreases faster than the monitoring point 1 , because the monitoring point 2 is located in the main direction of fracture propagation. After 50 days of drainage, the gas pressure at the monitoring point of the unfractured model dropped from $2 \mathrm{MPa}$ to $0.48 \mathrm{MPa}$, the gas pressure at monitoring point 1 of the fracturing model dropped to $0.22 \mathrm{MPa}$, and the gas pressure at monitoring point 2 dropped to $0.18 \mathrm{MPa}$. According to national standards, in order to eliminate the risk of gas outburst, the gas pressure should be reduced to below $0.74 \mathrm{MPa}$, and it takes 25 days for the gas pressure at the monitoring point of the unfractured model to fall below the standard. While for the fracturing model monitoring point 1 and monitoring point 2, it takes 8 days and 6 days respectively. 

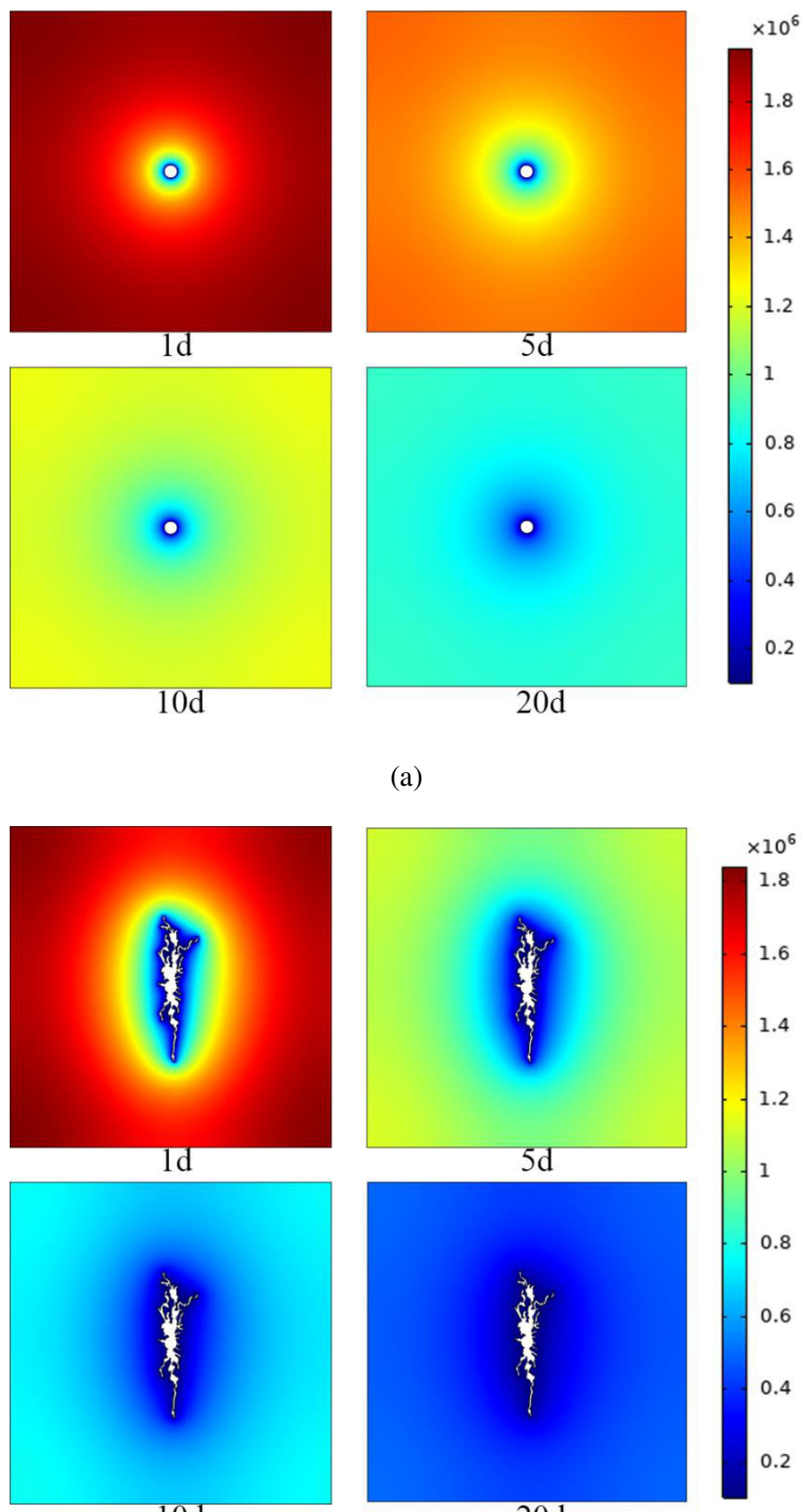

$10 \mathrm{~d}$
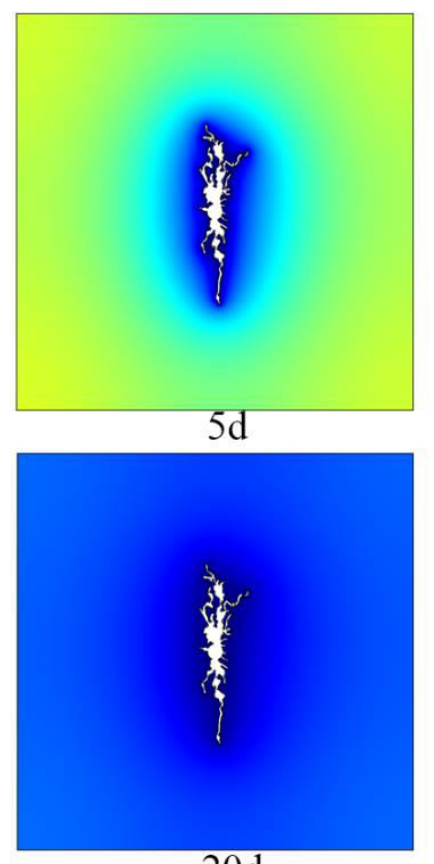

$20 \mathrm{~d}$ (a)
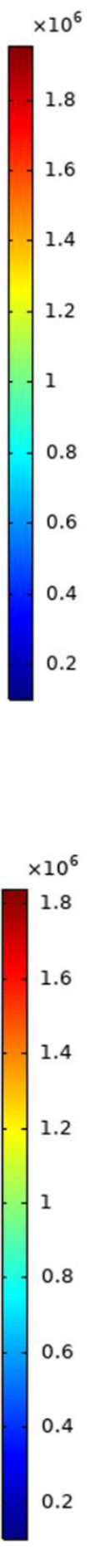

(b)

Fig. 10. The distribution of coal seam gas pressure at different times: (a) Unfractured model (b) Fractured model 


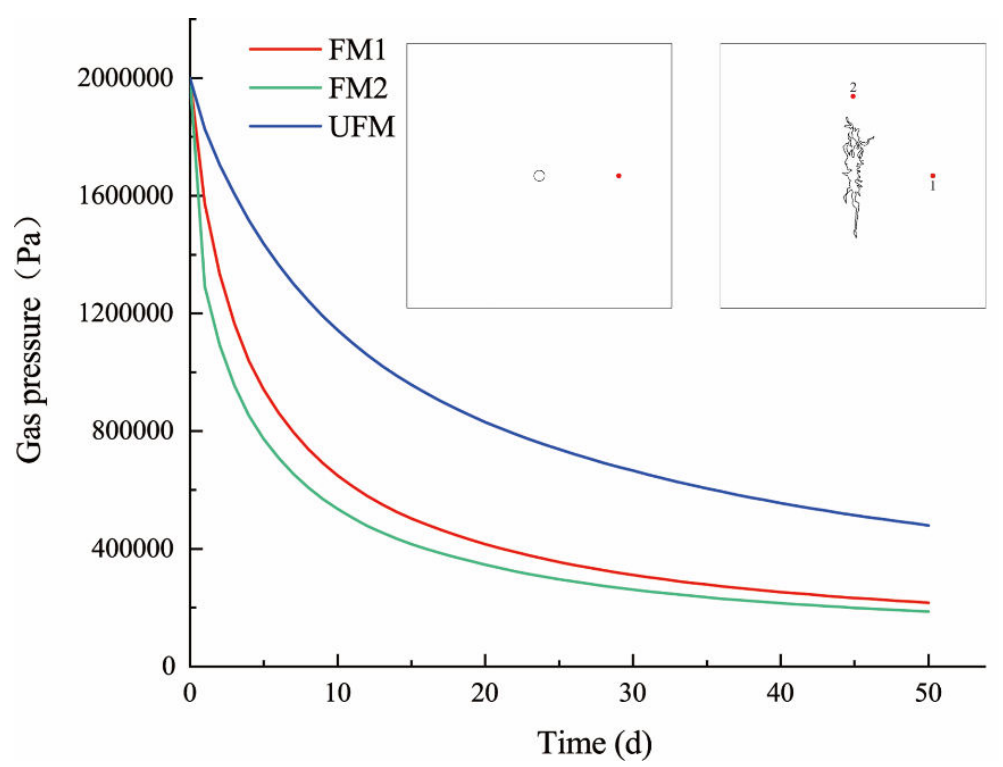

Fig. 11. Gas pressure variation curve with time at different monitoring points

Fig. 12(a) and Fig. 12(b) show the distribution of the permeability increase rate $\left(k-k_{0}\right) / k_{0}$ of the unfractured model and the fractured model at different times of drainage. The results show that with the increase of the extraction time, the permeability increase rate of the fracturing model is always greater than that of the unfracturing model. However, the increase rate of permeability in the fracturing model is different in the horizontal direction and the vertical direction, and the increase rate of the permeability in the main direction of fracture propagation is a bit larger. In order to quantitatively analyze the rate of change of permeability with time, a detection line was set between the points $(0,0)$ and $(2.5,0)$ of the unfractured model and the fractured model, as shown in Fig. 13 and Fig. 14. The results show that the far from the center point, the smaller the increase rate of permeability, the decrease rate gradually approaches 0 from fast to slow, and the permeability increase rate of the hydraulic fracturing model is always greater than that of the unfractured model. As the drainage time increases, the increase rate of permeability also increases significantly. After 20 days of drainage, the permeability at the center and edge of the unfractured model increased by $2.1 \%$ and $1.1 \%$, respectively, while the fractured model increased by $2.27 \%$ and $1.7 \%$, respectively. 


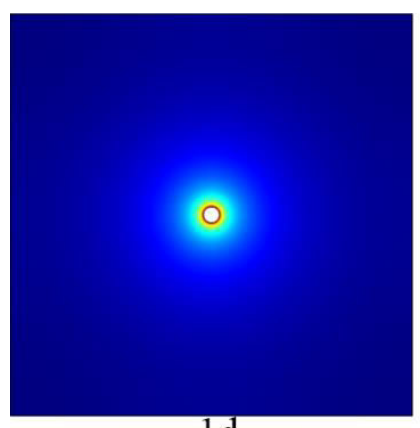

1d

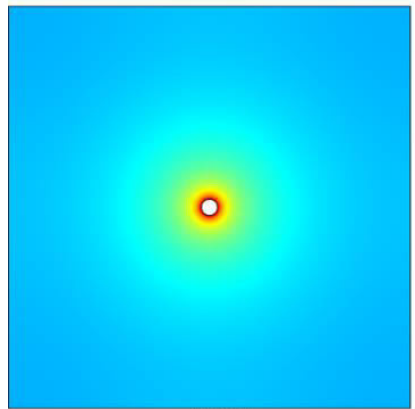

$10 \mathrm{~d}$
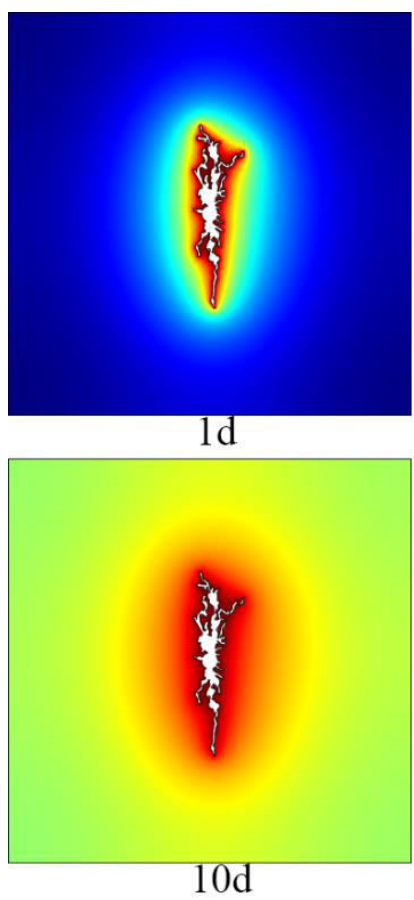

$10 \mathrm{~d}$

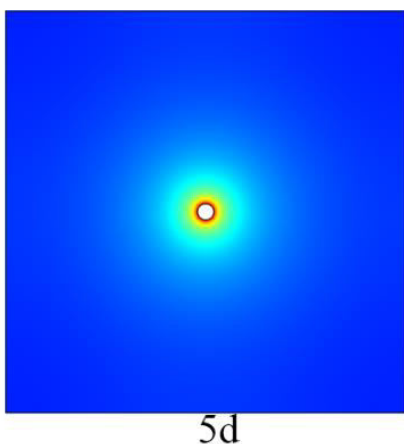

$5 d$

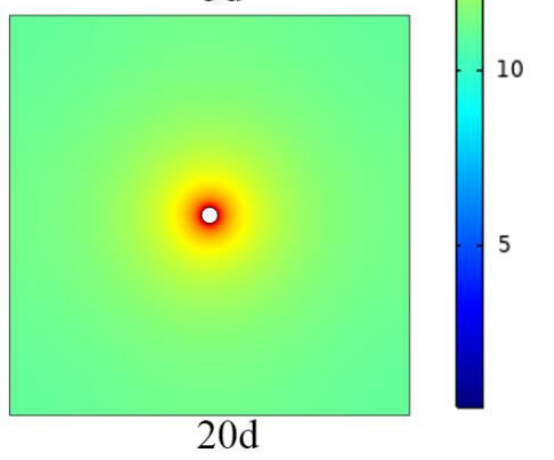

(a)

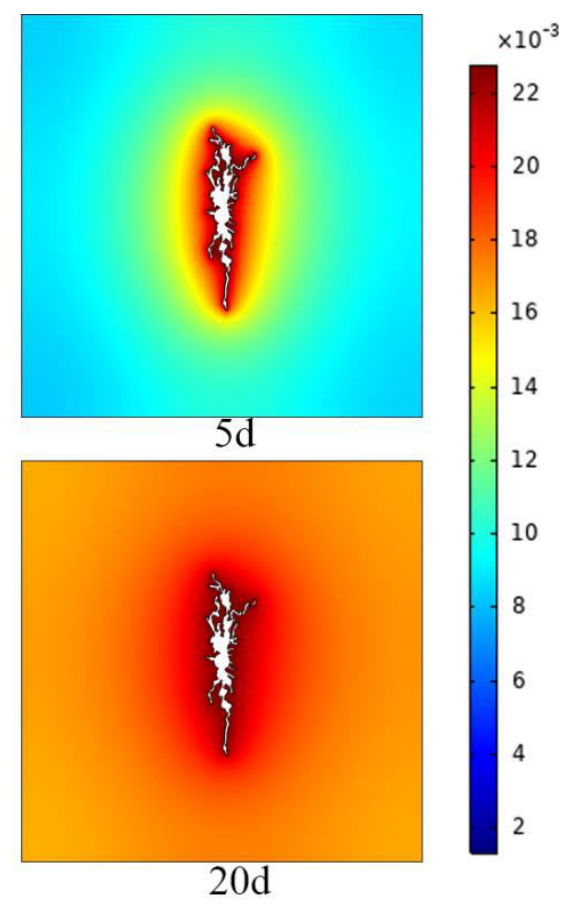

(b)

Fig. 12. The distribution of coal seam permeability increase rate at different times: (a) Unfractured model (b) Fractured model 


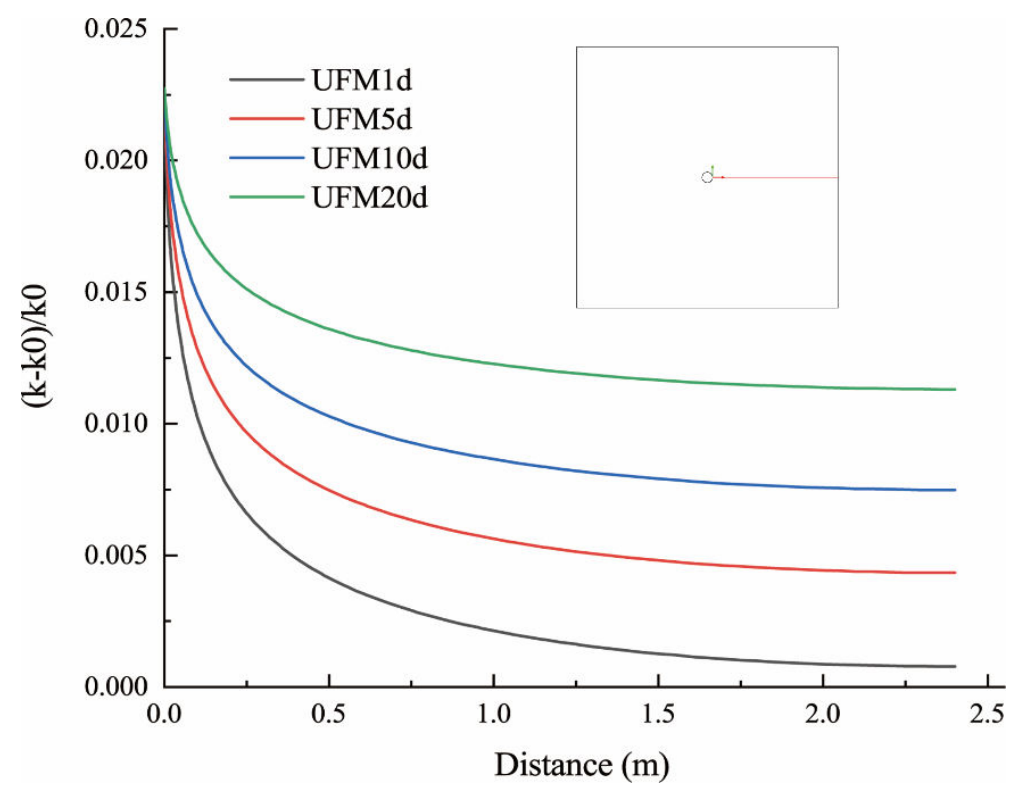

Fig. 13. Permeability increase rate change curve of the unfractured model

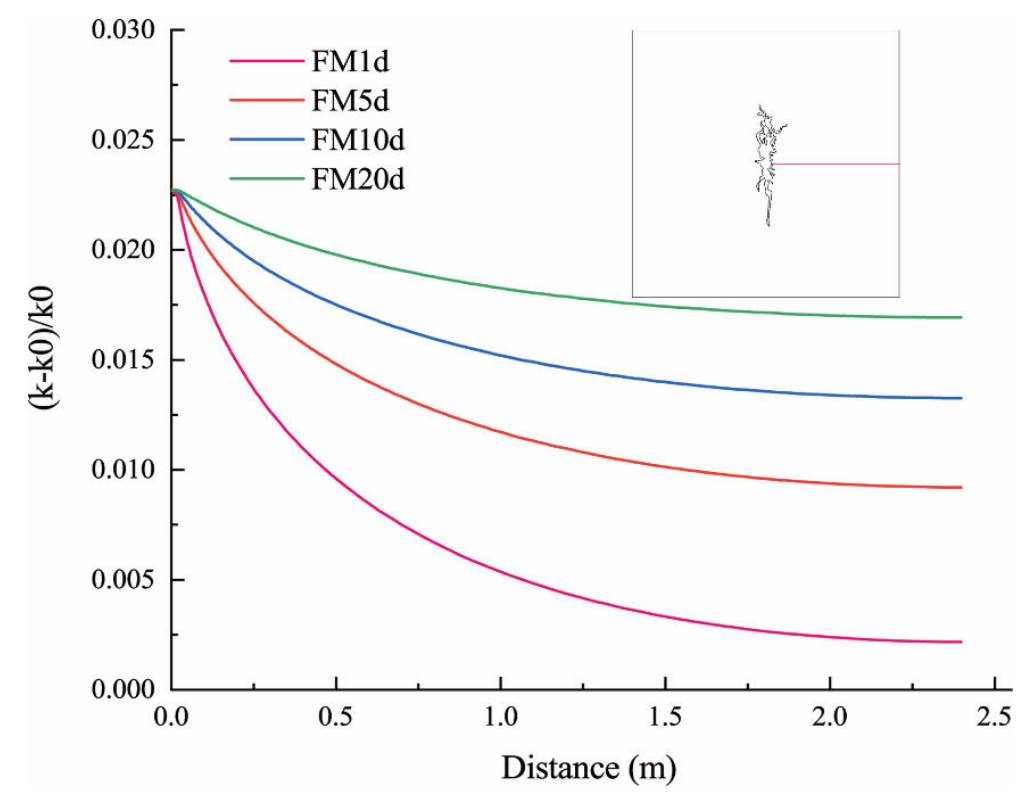

Fig. 14. Permeability increase rate change curve of fracturing model

\subsection{Different fracturing time}

Fig. 15(a) and Fig. 15(b) show the distribution of gas pressure and permeability increase rate at different time steps (S2 S5) of fracturing under different gas drainage times. The results show that as the drainage time increases, the gas pressure decreases and the permeability increase rate increases. Under different fracturing time steps, the gas pressure decrease rate and permeability increase rate in the direction of maximum principal stress (main direction of fracture propagation) are both greater than the direction of minimum principal stress. And as the fracturing time increases, this difference also increases. In order to 
qualitatively analyze the changes of gas pressure and permeability, two detection points are set in the S2 S5 model, namely monitoring point $1(1.5,0)$ and detection point $2(0,1.5)$. The gas pressure change curve at different fracturing time steps is shown in Fig. 16. The gas pressure decline trend of the four models is the same. The gas pressure drops rapidly in the early stage of drainage. As the drainage time increases, the gas pressure decline rate decreases sharply and tends to zero. The longer the fracturing time, the more complex the fracture network is, and the faster the gas pressure will drop. Moreover, as the fracturing time becomes longer, the difference between the horizontal and vertical gas pressure decreasing speeds becomes larger and larger, and the gas pressure decreasing speed in the direction of the maximum principal stress is significantly faster than the direction of the minimum principal stress. For gas pressure to drop below $0.74 \mathrm{MPa}$, it takes 13 days for both $\mathrm{S} 2$ model monitoring point 1 and monitoring point 2, 11 days and 10 days for S3 model, 10 and 9 days for S4 model, and 8 and 9 days for S5 model. The same is reduced below the standard, S3 and S5 require 11 days and 8 days respectively, and the fracturing time of S5 is more than twice that of S3. This also shows that with the increase of fracturing time, the influence of fracturing on gas drainage effect is decreasing. The change of permeability increase rate under different fracturing time steps is shown in Fig. 17. As the drainage time increases, the rate of increase in permeability changes from fast to slow. Since test point 2 is located in the main fracture propagation direction, the increase in permeability of test point 2 is always greater than that of test point 1 , and as the fracturing time becomes longer, this difference becomes larger and larger. However, this difference will gradually decrease as the extraction time increases.
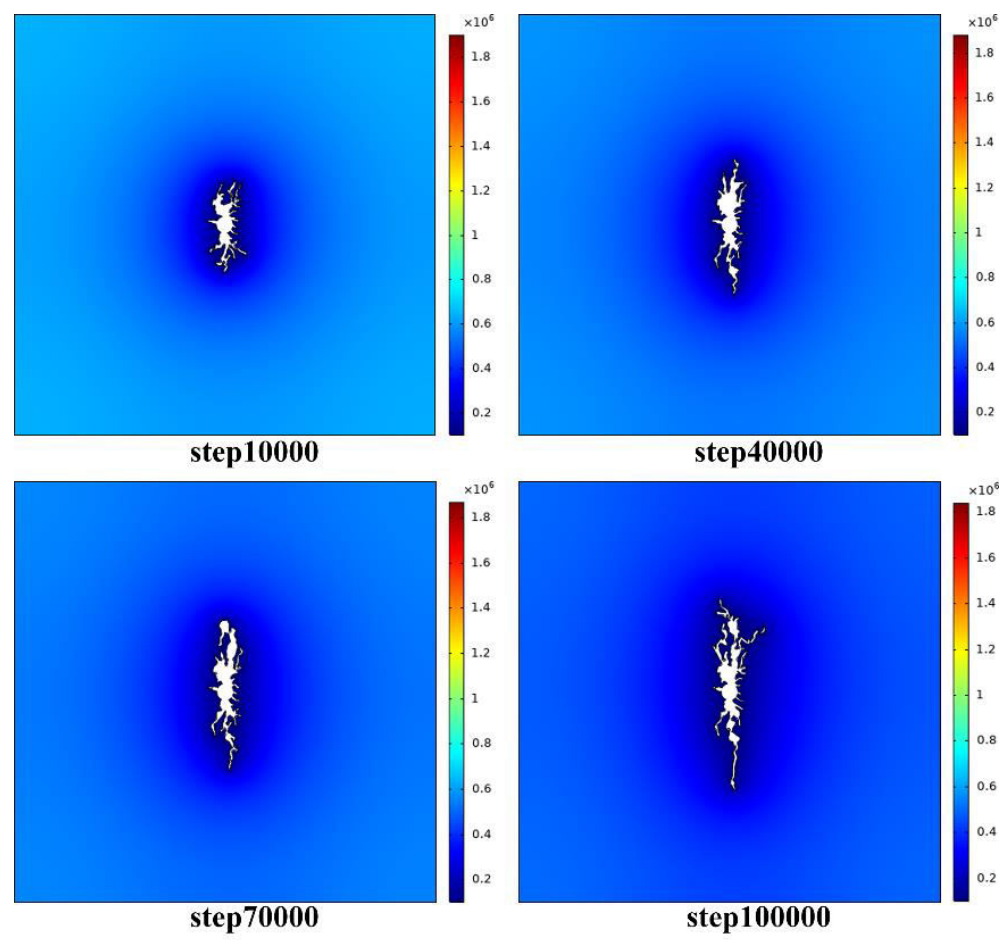
(a)

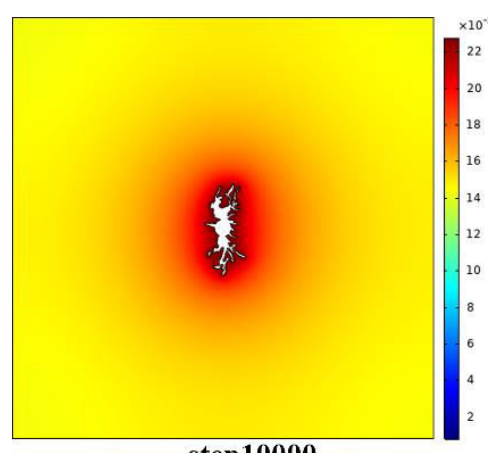

step 10000

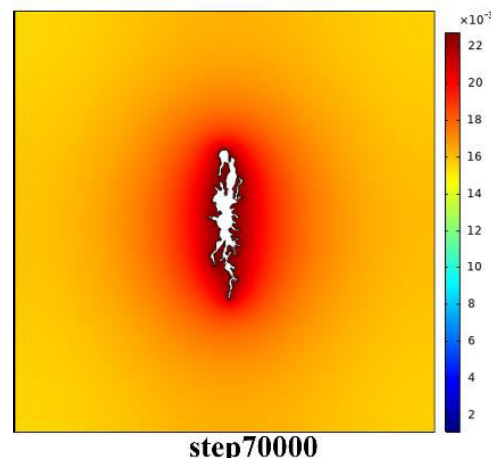

step 70000

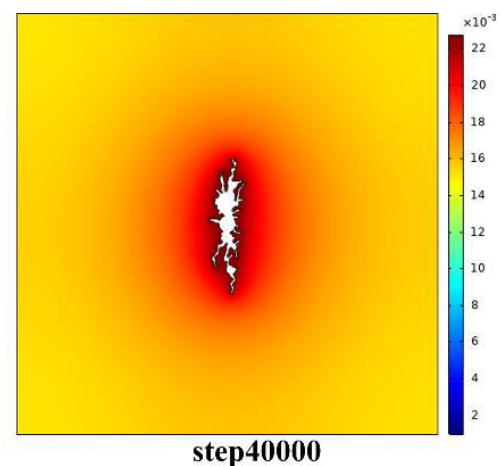

step40000

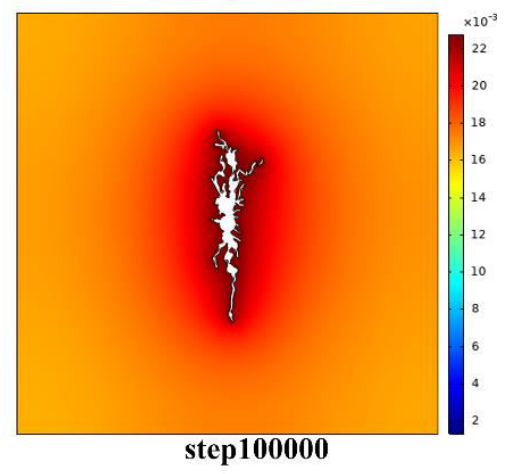

(b)

Fig. 15. The distribution of different fracturing time steps after 20 days of pumping: (a) Gas pressure (b) Permeability increase rate

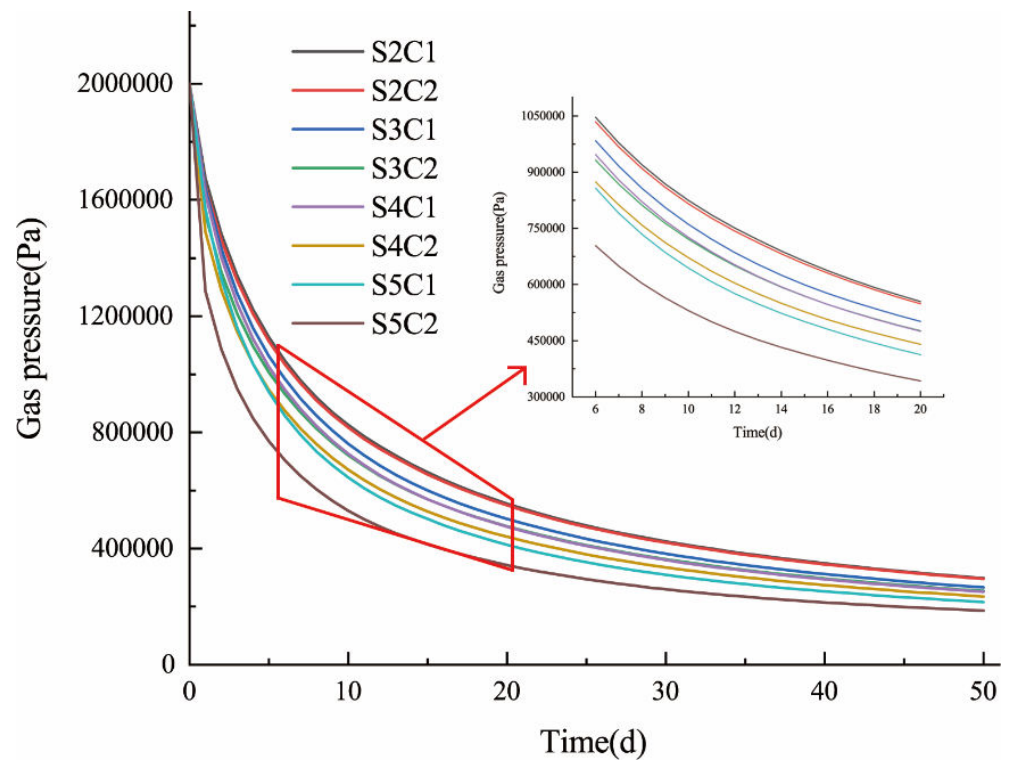

Fig. 16. Gas pressure variation curve at different fracturing time steps 


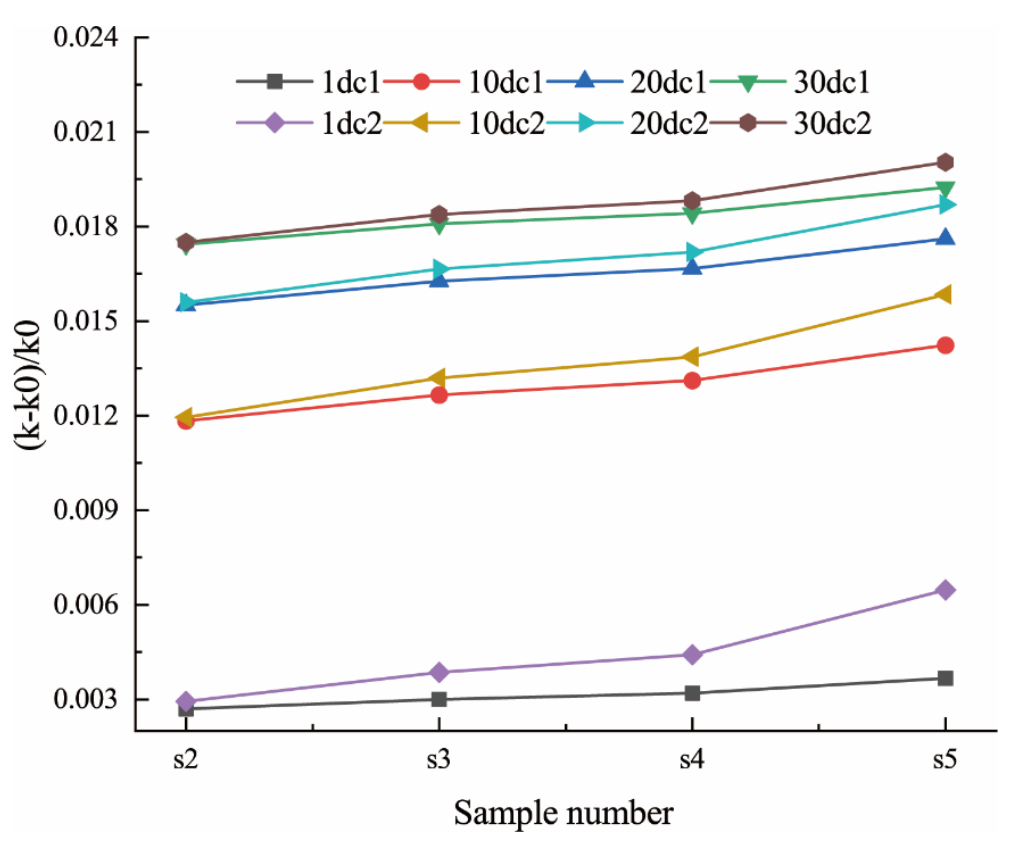

Fig. 17. Variation curve of permeability increase rate at different fracturing time steps

\subsection{Different initial pore pressures}

In order to qualitatively analyze the changes of gas pressure and permeability, two detection points are set in the S5 S8 model, namely monitoring point $1(1.5,0)$ and detection point $2(0,1.5)$. Fig. 18 shows the gas pressure changes of different initial pore pressure models (S5 S8). The results show that with the increase of the extraction time, the gas pressure decline rate changes from fast to slow, and the gas pressure difference between test point 1 and test point 2 gradually weakens. The greater the initial pore pressure, the faster the gas pressure will drop, and the gas pressure will approach the set orifice pressure as the extraction time increases. For gas pressure to drop below $0.74 \mathrm{MPa}$, it takes 8 and 6 days for S5 model monitoring point 1 and monitoring point 2, 10 and 7 days for S6 model, 10 and 8 days for S7 model, and 11 and 8 days for S8 model. The S8 model increased the initial pore pressure by 1.5 times compared with the S5 model, but after fracturing, the gas pressure drops below the standard by drainage and it only takes 3 more days to extract. Fig. 19 shows the change curve of permeability increase rate of different initial pore pressure models. The results show that the permeability increase trend of different initial pore pressure models is consistent. The permeability increases rapidly at the beginning of the drainage, but the increase rate of the permeability rapidly decays and approaches zero as the drainage time increases. The greater the initial pore pressure, the greater the increase in permeability. However, the influence of the initial pore pressure on the increase in permeability will gradually become smaller. 


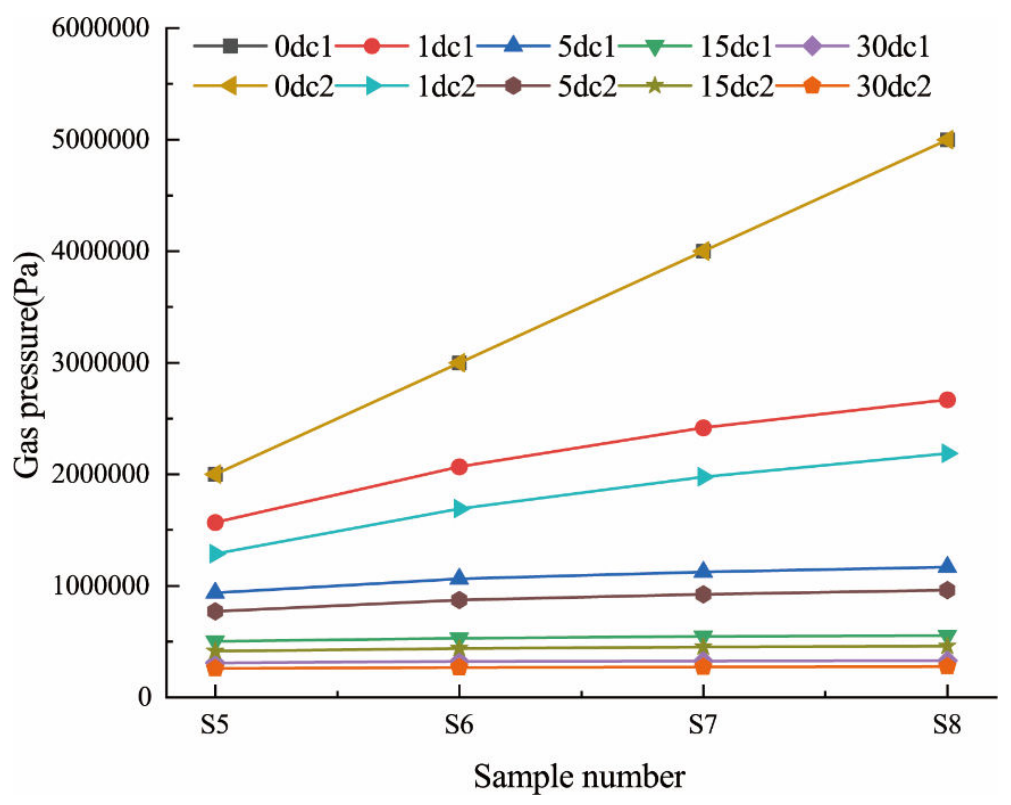

Fig. 18. Gas pressure variation curves of different initial pore pressure models

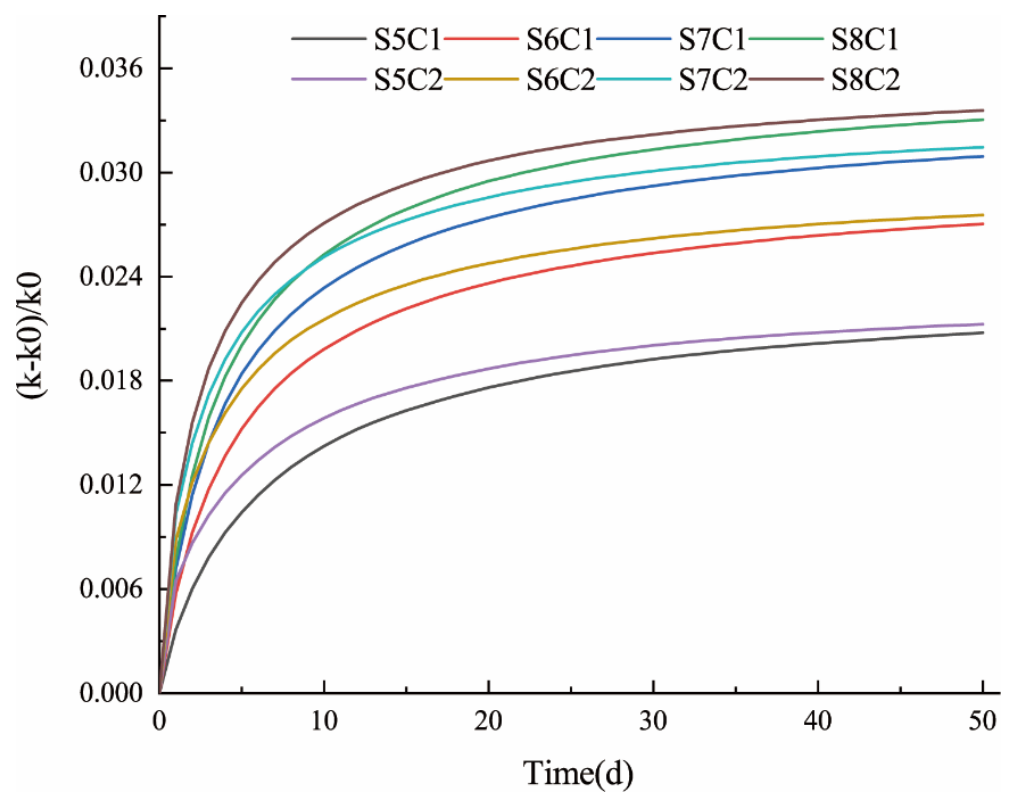

Fig. 19. Permeability increase rate change curve of different initial pore pressure models

\subsection{Application prospect}

In this work, the influence of hydraulic fracturing on coal seam permeability under different fracturing times and different initial pore pressures are simulated and analyzed. The research results show that hydraulic fracturing can increase the permeability of the coal seam and improve the gas drainage effect, but as the fracturing time increases, the impact of fracturing on the gas drainage effect is decreasing. The research results could predict the increase effect of hydraulic fracturing on coal 
seam permeability, guide the site to reasonably reduce the fracturing time while ensuring the increase effect, and then help the site to reasonably reduce the drilling volume and gas extraction time. The greater the initial gas pressure, the faster the gas pressure drops and the greater the increase in permeability. The results can be used to guide hydraulic fracturing to enhance permeability in mines with different gas content.

Affected by in-situ stress, the main direction of fracture propagation is the direction of maximum principal stress, which results in a difference in permeability changes between horizontal and vertical directions, and this difference will become greater as the fracturing time becomes longer. Eliminating or exploiting this difference will be our next subject to be studied.

\section{Conclusion}

In this work, a hydraulic fracturing fluid-solid coupling model was established. A mathematical coupling model of the interaction between coal seam deformation and gas flow was established, and the effect of hydraulic fracturing was simulated numerically. The research conclusions can be summarized as follows:

(1) As the fracturing time increases, the rate of fracture propagation changes from fast to slow. Moreover, the crack propagation is discontinuous, and the pressure at the tip of the crack is not enough to damage the coal body for a certain period of time, and the crack will continue to expand after the pressure accumulates to the breaking pressure. The particles are all moving in the direction of the minimum principal stress, and the main fractures are expanding in the direction of the maximum principal stress. The closer to the injection hole, the greater the displacement, and the more adequate the fracture expansion.

(2) The gas pressure change trend of the fracturing model and the unfractured model is the same. The gas pressure decreases rapidly at the beginning of the drainage, but the rate of decrease of the gas pressure decreases rapidly with the increase of the drainage time. The gas pressure decrease rate and permeability increase rate of the fracturing model are significantly greater than those of the unfractured model. However, the gas pressure and permeability of the fracturing model vary in the horizontal and vertical directions.

(3) The longer the fracturing time is, the more complex the fracture network is, the faster the gas pressure decreases and the permeability increases, and the difference between horizontal and vertical directions will become greater and greater. However, with the increase of extraction time, this difference will gradually decrease. With the increase of fracturing time, the impact of fracturing on gas drainage effect is also decreasing.

(4) The greater the initial pore pressure, the faster the gas pressure drops, and the gas pressure will approach the orifice pressure as the extraction time increases. The increasing trend of the permeability of S5 S8 models is the same. The 
permeability increases rapidly at the initial stage of drainage, but the increase rate of permeability decreases rapidly as the drainage time increases. The greater the initial pore pressure, the greater the increase in permeability, but the influence of the initial pore pressure on the increase in permeability will gradually become smaller. 


\section{CRediT authorship contribution statement}

Kai Wang: Methodology, Investigation, Writing-original draft. Guodong Zhang: Formal analysis, Writing-review \& editing. Yanhai Wang: Formal analysis, Writing. Xiang Zhang: Investigation, Formal analysis. Kangnan Li: Investigation. Wei Guo: Formal analysis. Feng Du: Conceptualization, Formal analysis, Review \& editing.

\section{Declaration of Competing Interest}

The authors declare that they have no known competing financial interests or personal relationships that could have appeared to influence the work reported in this paper.

\section{Acknowledgements}

This work was supported by National Natural Science Foundation of China (51874314, 52004291).

\section{Reference}

[1] Liu Yk, Zhou Fb, Liu L, Liu C, Hu Sy. An experimental and numerical investigation on the deformation of overlying coal seams above double-seam extraction for controlling coal mine methane emissions. International Journal of Coal Geology 2011;87(2):139-49.

[2] Wang H, Cheng Y, Yuan L. Gas outburst disasters and the mining technology of key protective seam in coal seam group in the Huainan coalfield. Natural Hazards 2013;67(2):763-82.

[3] Al-Rubaie A, Ben Mahmud HK. A numerical investigation on the performance of hydraulic fracturing in naturally fractured gas reservoirs based on stimulated rock volume. Journal of Petroleum Exploration and Production Technology 2020;10(8):3333-45.

[4] Du F, Wang K, Zhang X, Xin C, Shu L, Wang G. Experimental Study of Coal-Gas Outburst: Insights from Coal-Rock Structure, Gas Pressure and Adsorptivity. Natural Resources Research 2020;29(4):2481-93.

[5] Huang B, Liu J. Fully three-dimensional propagation model of horizontal borehole hydraulic fractures in strata under 
the effect of bedding planes. Energy Exploration \& Exploitation 2018;36(5):1189-209.

[6] Liu B, Jin Y, Chen M. Influence of vugs in fractured-vuggy carbonate reservoirs on hydraulic fracture propagation based on laboratory experiments. Journal of Structural Geology 2019;124:143-50.

[7] Wang S, Li H, Li D. Numerical Simulation of Hydraulic Fracture Propagation in Coal Seams with Discontinuous Natural Fracture Networks. Processes 2018;6(8):113-21.

[8] He H, Dou L, Fan J, Du T, Sun X. Deep-hole directional fracturing of thick hard roof for rockburst prevention. Tunnelling and Underground Space Technology 2012;32:34-43.

[9] Huang B, Wang Y, Cao S. Cavability control by hydraulic fracturing for top coal caving in hard thick coal seams. International Journal of Rock Mechanics and Mining Sciences 2015;74:45-57.

[10] Li X-S, Xu C-G, Zhang Y, Ruan X-K, Li G, Wang Y. Investigation into gas production from natural gas hydrate: A review. Applied Energy 2016;172:286-322.

[11] Wang K, Du F, Wang G. Investigation of gas pressure and temperature effects on the permeability and steady-state time of chinese anthracite coal: An experimental study. Journal of Natural Gas Science and Engineering 2017;40:179-88.

[12] Cheng Y, Lu Y, Ge Z, Cheng L, Zheng J, Zhang W. Experimental study on crack propagation control and mechanism analysis of directional hydraulic fracturing. Fuel 2018;218:316-24.

[13] Zhang J. Numerical simulation of hydraulic fracturing coalbed methane reservoir. Fuel 2014;136:57-61.

[14] Wang T, Zhou W, Chen J, Xiao X, Li Y, Zhao X. Simulation of hydraulic fracturing using particle flow method and application in a coal mine. International Journal of Coal Geology 2014;121:1-13.

[15] Wang S, Li H, Li D. Numerical Simulation of Hydraulic Fracture Propagation in Coal Seams with Discontinuous Natural Fracture Networks. Processes 2018;6(8):113-27.

[16] Lyu S, Wang S, Chen X, Wang S, Wang T, Shi X, et al. Natural fractures in soft coal seams and their effect on hydraulic fracture propagation: A field study. Journal of Petroleum Science and Engineering 2020;192.

[17] Yuan Z, Wang H, Liu N, Liu J. Simulation Study of Characteristics of Hydraulic Fracturing Propagation of Low Permeability Coal Seam. Disaster Advances 2012;5(4):717-20.

[18] Zhao H, Wang X, Liu Z. Experimental investigation of hydraulic sand fracturing on fracture propagation under the influence of coal macrolithotypes in Hancheng block, China. Journal of Petroleum Science and Engineering 2019;175:60-71.

[19] Adachi A, Siebrits E, Peirce A, Desroches J. Computer simulation of hydraulic fractures. International Journal of Rock 
Mechanics and Mining Sciences 2007;44(5):739-57.

[20] Li Q, Lin B, Zhai C. The effect of pulse frequency on the fracture extension during hydraulic fracturing. Journal of Natural Gas Science and Engineering 2014;21:296-303.

[21] Liang Y, Cheng Y, Zou Q, Wang W, Ma Y, Li Q. Response characteristics of coal subjected to hydraulic fracturing: An evaluation based on real-time monitoring of borehole strain and acoustic emission. Journal of Natural Gas Science and Engineering 2017;38:402-11.

[22] Zhang Z, Wang H, Deng B, Li M, Zhang D. Field Investigation of Hydraulic Fracturing in Coal Seams and Its Enhancement for Methane Extraction in the Southeast Sichuan Basin, China. Energies 2018;11(12).

[23] Huang BX, Huang CM, Cheng QY, Huang CH, Xue WC. Hydraulic fracturing technology for improving permeability in gas-bearing coal seams in underground coal mines. Journal of the Southern African Institute of Mining and Metallurgy 2012;112(6):485-95.

[24] Xu J, Zhai C, Qin L. Mechanism and application of pulse hydraulic fracturing in improving drainage of coalbed methane. Journal of Natural Gas Science and Engineering 2017;40:79-90.

[25] Li Q, Lin B, Zhai C. A new technique for preventing and controlling coal and gas outburst hazard with pulse hydraulic fracturing: a case study in Yuwu coal mine, China. Natural Hazards 2015;75(3):2931-46.

[26] Shimizu H, Murata S, Ishida T. The distinct element analysis for hydraulic fracturing in hard rock considering fluid viscosity and particle size distribution. International Journal of Rock Mechanics and Mining Sciences 2011;48(5):712-27.

[27] Hubbert MK, Willis, D.G. Mechanics of hydraulic fracturing. Pet. Trans. AIME 201. 1957;153-166.

[28] Xie N, Yang J, Shao J. Study on the hydromechanical behavior of single fracture under normal stresses. Ksce Journal of Civil Engineering 2014;18(6):1641-9.

[29] Zhang L, Lu G, Chang C, Wu J, Zhao Y, Liu W. Numerical simulation of a coupled gas flow and geomechanics process in fractured coalbed methane reservoirs. Energy Science \& Engineering 2019;7(4):1095-105.

[30] Zhang H, Liu J, Elsworth D. How sorption-induced matrix deformation affects gas flow in coal seams: A new FE model. International Journal of Rock Mechanics and Mining Sciences 2008;45(8):1226-36.

[31] Mi L, Jiang H, Mou S, Li J, Pei Y, Liu C. Numerical simulation study of shale gas reservoir with stress-dependent fracture conductivity using multiscale discrete fracture network model. Particulate Science and Technology 2018;36(2):202-11. 
[32] Kumar H, Elsworth D, Mathews JP, Marone C. Permeability evolution in sorbing media: analogies between organic-rich shale and coal. Geofluids 2016;16(1):43-55.

[33] Pan Z, Connell LD. Modelling permeability for coal reservoirs: A review of analytical models and testing data. International Journal of Coal Geology 2012;92:1-44. 